\title{
Gamificando a sala de aula: desafios e possibilidades em uma disciplina experimental de Pensamento Computacional no ensino fundamental
}

\author{
Tancicleide C. S. Gomes ${ }^{1}$, Patricia C. de A. R. Tedesco ${ }^{1}$ \\ ${ }^{1}$ Centro de Informática - Universidade Federal de Pernambuco (UFPE) \\ Recife - PE - Brasil \\ tancicleide.gomes@gmail.com, pcartecin.ufpe.br
}

\begin{abstract}
The use of game elements in education, when well planned, makes the interesting failure and keeps the participants engaged and optimistic. According to the literature, these characteristics are relevant in introductory programming experiments. The present study reports an ongoing experiment that investigates the use of gamification in computational thinking in elementary school. The initial results show that the approach developed, while considered fun, is not sufficiently engaging for older students.
\end{abstract}

Resumo. O uso de elementos de jogos na educação, quando bem planejado, torna o fracasso interessante e mantém os participantes engajados e otimistas. De acordo com a literatura, essas características são relevantes em experiências introdutórias de programação. $O$ presente estudo relata uma experiência em andamento que investiga o uso da gamificação em uma disciplina de pensamento computacional no ensino fundamental. Os resultados iniciais encontrados mostram que a abordagem desenvolvida, apesar de ser considerada divertida não se mostra suficientemente engajadora para os alunos mais velhos.

\section{Introdução}

Segundo McGonigal (2012), os jogos despertam emoções positivas, deixam os jogadores intensamente envolvidos e parecem minimizar o medo de fracassar. Nicole Lazzaro [citada por McGonigal 2012] afirma que os jogadores passam aproximadamente $80 \%$ das horas jogadas fracassando. Ou seja, quando os jogos são bem elaborados, tornam o fracasso empolgante e deixam os jogadores interessados e otimistas, de modo que eles jogam novamente na esperança de alcançar o sucesso. Se considerados os desafios comumente relatados na literatura em experiências iniciais de programação, estas características dos jogos são especialmente importantes.

Os elementos de design de jogos possuem características que possibilitam estruturar ambientes de aprendizagem mais prazerosos cuja pedagogia fomenta uma mentalidade incremental que: encoraja a prática, valoriza o esforço e incorpora o erro como parte do processo de aprendizado. Contudo, um dos principais desafios da gamificação na educação é usar adequadamente os estilos, dinâmicas e o teor lúdico dos jogos para engajar efetivamente os sujeitos em situações de aprendizagem. 
Neste trabalho relatamos uma experiência em andamento da gamificação de uma disciplina experimental de Pensamento Computacional com onze turmas do sexto ao nono ano do ensino fundamental em uma escola da rede particular de ensino. Este trabalho está organizado da seguinte forma: na seção 2 são apresentados os construtos teóricos que norteiam este estudo. Os principais trabalhos nacionais relacionados são descritos na seção 3. Na seção 4 são descritos o design do estudo, contexto, participantes e os passos realizados para a elaboração e implantação do modelo de gamificação. Os primeiros resultados, percepções e desafios encontrados são apresentados e discutidos na seção 5. Considerações finais são apresentadas na seção 6.

\section{Fundamentos Teóricos}

Nesta seção são apresentados os principais referenciais teóricos que fundamentam o desenvolvimento deste trabalho.

\subsection{Gamificação}

O termo gamificação recebeu diversas conceituações, mas neste trabalho adotaremos a seguinte definição: "o uso de elementos (em contraste ao uso de jogos propriamente ditos) de design (ao invés de tecnologias baseadas em jogos) de jogos (ao invés de apenas atividades lúdicas ou brincadeiras) em contextos de não jogo" [Deterding et al. 2011]. Segundo Lee e Hammer (2011) apud Seixas et al. (2014), a gamificação no contexto escolar visa oferecer oportunidades para minimizar problemas de motivação e engajamento dos alunos. Ou seja, utilizar elementos de design de jogos no intuito de estruturar "cenários de aprendizagem mediados pelo desafio, prazer e entretenimento" [Alves, Minho e Diniz 2011].

Existe uma série de elementos de design de jogos que podem ser incorporados: avatares, recursos colecionáveis, recompensas, níveis (sistema de progressão), desbloqueio de conteúdo, combates e outros. No entanto, os elementos de jogos mais utilizados são pontos, insígnias e rankings (do acrônimo em inglês PBL - points, badges, leaderboards). O uso indiscriminado dos componentes PBL é considerado uma visão reducionista [Chou 2015 apud Schlemmer e Lopes 2016] e alguns autores afirmam que ao adotar apenas estes elementos não se pode sequer considerar como gamificação [Werbach e Hunter 2012 apud Lima 2017].

Segundo Schlemmer e Lopes (2016), o uso dos componentes PBL tornam a estruturação da gamificação mais fácil, escalável e de baixo custo. Contudo, a sua utilização de maneira descontextualizada pode ser problemática por concentrar-se em uma camada de motivação extrínseca que pode funcionar de maneira adequada para os alunos mais jovens, porém não observa-se o mesmo para os alunos mais velhos, sobretudo quando consideram-se experiências de longo prazo.

Quando questiona-se aos jogadores o porquê deles gostarem de jogar, eles não se referem aos elementos PBL, mas aos desafios, às missões, às estratégias [Veen e Vracking]. Deste modo, em uma estratégia de gamificação é necessário compreender o 
VI Congresso Brasileiro de Informática na Educação (CBIE 2017)

Anais do XXIII Workshop de Informática na Escola (WIE 2017)

problema a ser resolvido, o contexto, o ambiente e os sujeitos envolvidos a fim de estruturar desafios e missões condizentes com os objetivos pessoais dos 'jogadores' [Schlemmer e Lopes 2016].

\subsection{Modelo de Gamificação}

O modelo de gamificação adotado neste trabalho baseia-se na adaptação proposta por Lima (2017) para o framework de gamificação de Werbach e Hunter (2012). No modelo proposto por Lima (2017), são sugeridas seis fases para desenvolver uma estratégia de gamificação: 1) delimitação dos objetivos; 2) delimitação dos objetivos comportamentais que se deseja promover nos jogadores; 3) descrição dos jogadores; 4) definição das atividades de repetição; 5) dedicação à diversão; 6) definição das ferramentas apropriadas.

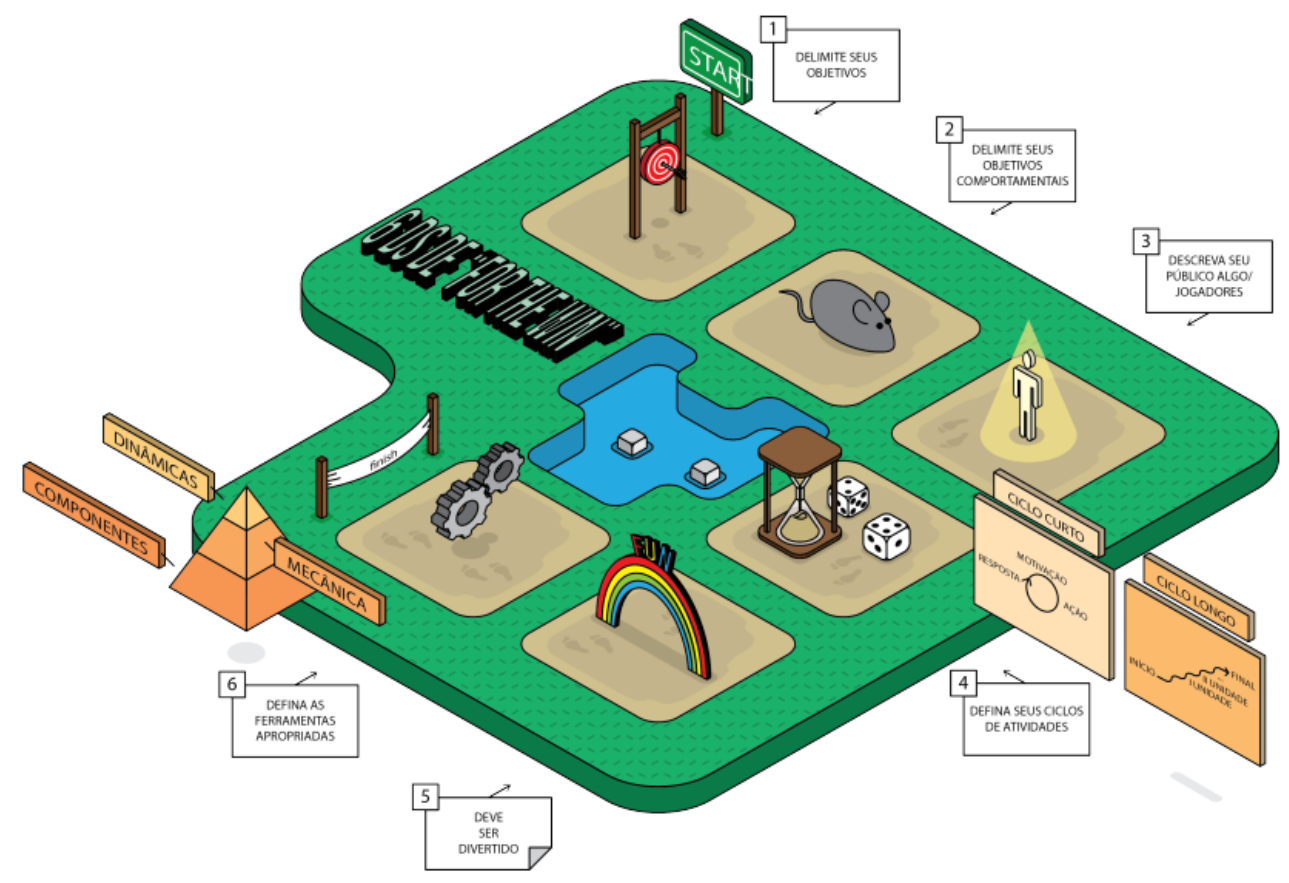

Figura 1. Modelo de gamificação proposto por Werbach e Hunter (2012). Fonte: Lima (2017)

Lima (2017) propôs adaptações no modelo para adequá-lo ao contexto educacional e incorporou propostas de estudiosos de design de jogos, especialmente nas fases (4) e (5). Na nossa instância deste modelo procuramos incluir as preferências de entretenimento dos estudantes para nortear a estruturação da gamificação.

\section{Trabalhos Relacionados}

O interesse pelo uso de jogos e seus elementos em contextos educacionais tem crescido nos últimos anos. O mapeamento sistemático desenvolvido por Borges et al. (2013) aponta que boa parte dos estudos relacionados foram realizados em instituições de ensino superior (46\%), com apenas dois estudos voltados ao ensino fundamental ( $8 \%$ ) e outros $23 \%$ sem determinarem o nível educacional. Os autores não encontraram estudos 
desenvolvidos ou voltados para a educação infantil, ensino médio ou mesmo para portadores de necessidades especiais. Os estudos encontrados mapeados por eles têm como principal objetivo investigar sobre os seguintes tópicos: (1) Aprimoramento de habilidades; (2) Desafios; (3) Guidelines; (4) Promoção do Engajamento; (5) Maximização do aprendizado; (6) Mudança de comportamento; (7) Socialização.

Figueiredo, Paz e Junqueira (2015) revisaram os estudos publicados entre 2009 e 2014 no Simpósio Brasileiro de Games e Entretenimento Digital (SBGames). Foram contemplados ainda os trabalhos publicados entre 2000 e 2013 no Portal de Teses e Dissertações da Coordenação de Aperfeiçoamento Pessoal de Nível Superior (CAPES). Os autores encontraram apenas dois trabalhos sobre gamificação na educação nos anais do SBGames e o levantamento realizado no Portal da CAPES apresentou apenas um estudo envolvendo gamificação e educação. O que assevera o quanto os estudos relacionados a esta temática são incipientes no cenário nacional.

Os estudos nacionais encontrados que abordam a gamificação no ensino de programação concentram-se na adoção de elementos estruturais de design de jogos como: recursos colecionáveis e recompensas [Aguiar 2015; Brito e Madeira 2015; Campos, Gardiman e Madeira 2015; Falcão, Leite e Tenório 2014; Maekawa, Nagai e Izeki 2015; Raposo e Dantas 2016; Silva, Melo e Tedesco 2016]. Mesmo no trabalho de Maekawa, Nagai e Izeki (2015), em que a narrativa de Star Wars inspirou as nomenclaturas do curso desenvolvido e os níveis de progressão do aluno. No entanto, os elementos narrativos serviram unicamente como pano de fundo para os componentes PBL. Os autores também não explicitam a justificativa pela escolha desta narrativa: se as preferências de entretenimento dos estudantes foram consideradas, por exemplo.

Outro aspecto observado: entre os estudos encontrados, apenas um deles contempla as características pessoais dos alunos no intuito de prover uma experiência de gamificação individualizada [Silva, Melo e Tedesco 2015]. O principal diferencial deste trabalho em relação aos demais consiste na adoção de uma variada gama de componentes, mecânicas e dinâmicas de jogos. Outro diferencial consiste no fato de que adotamos as preferências de entretenimento dos estudantes para auxiliar na criação das dinâmicas de jogos. Não foram encontrados outros trabalhos que tratem sobre a gamificação de uma disciplina de Pensamento Computacional ou semelhante em contexto similar ao descrito neste trabalho.

\section{Design do Estudo}

O presente trabalho faz parte de uma pesquisa-ação. Em razão da natureza do fenômeno investigado adotamos uma abordagem mista que integra técnicas quantitativas e qualitativas para a coleta e análise dos dados como: observação-participante e questionários. Nas subseções a seguir são descritos o contexto, os participantes, as ferramentas utilizadas, os procedimentos desenvolvidos: o modelo de gamificação adotado e os passos realizados.

\subsection{Contexto e Participantes}

Este estudo tem sido desenvolvido em uma escola da rede particular de ensino de 
VI Congresso Brasileiro de Informática na Educação (CBIE 2017)

Anais do XXIII Workshop de Informática na Escola (WIE 2017)

Recife, Pernambuco. Na referida escola, existem três turmas de $6^{\circ} \mathrm{s}, 7^{\circ} \mathrm{s}$ e $8^{\circ} \mathrm{s}$ anos cada e duas turmas de $9^{\circ}$ ano, totalizando 263 alunos de ambos os sexos com idades entre 10 e 17 anos. Neste ano, foi concebida a disciplina de Pensamento Computacional que integra conteúdos de Ciência da Computação, Tecnologia da Informação e Letramento Digital.

Os objetivos educacionais foram traçados a partir do currículo de referência CSTA K-12 Computer Science Standards ${ }^{1}$ para ensino de Ciência da Computação na educação básica da . Como a disciplina possui carga horária de 40 horas/ano, foram considerados apenas os objetivos relacionados aos tópicos de Algoritmos e Programação. Os encontros da referida disciplina têm periodicidade semanal e duração de 50 minutos, realizadas no laboratório de informática da escola, que conta com 28 computadores de mesa com acesso à internet.

\subsection{Plataforma web}

Neste trabalho adotamos a plataforma online Classcraft para apoiar a execução da gamificação da disciplina. O objetivo foi permitir que o aluno pudesse ter um feedback constante e mais preciso sobre o seu desempenho na disciplina. No mais, optou-se por esta plataforma porque a consideramos uma das mais adequadas mediante as preferências de entretenimento relatadas pela maioria dos alunos nos questionários para designação do perfil $1^{3}$.

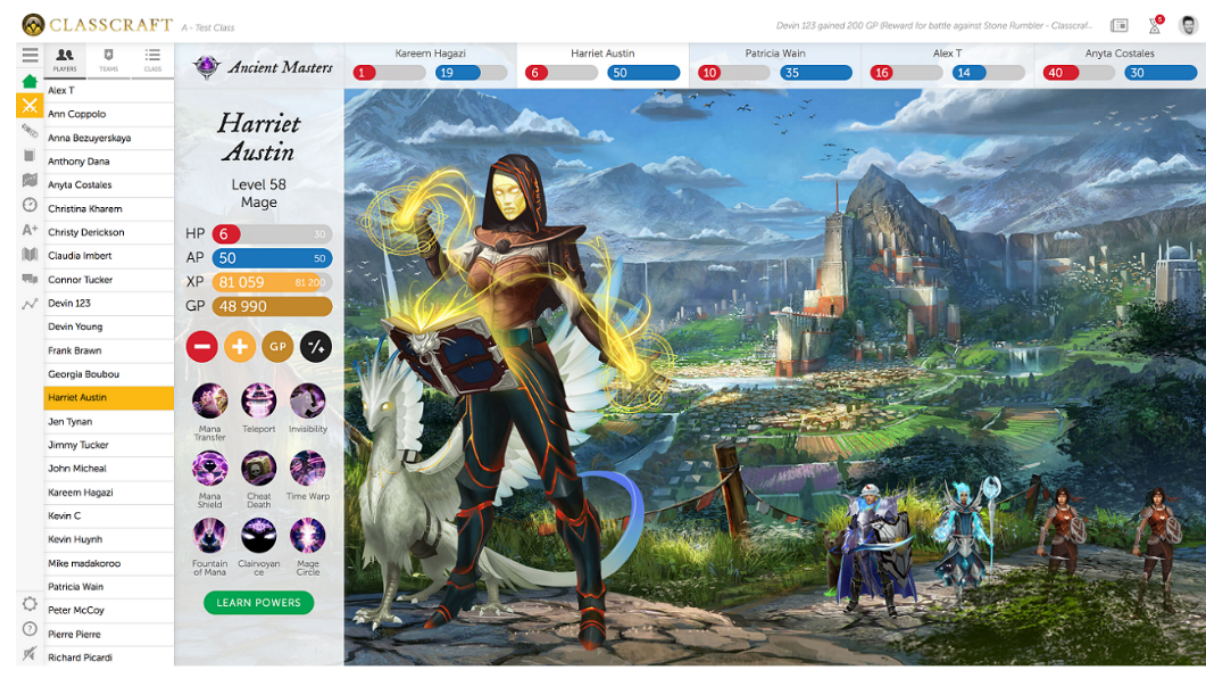

Figura 2. Classcraft: Exemplo de página inicial de um estudante

O Classcraft oferece um sistema de pontuação abrangente, cujas regras podem ser personalizadas pelo professor para cada uma das turmas. O sistema oferece

\footnotetext{
${ }^{1}$ Este currículo, até a submissão deste trabalho, está disponível apenas em sua versão provisória no site oficial: https://www.csteachers.org/page/CSTA_Standards

${ }^{2}$ https://www.classcraft.com/

${ }^{3} \mathrm{O}$ Classcraft oferece uma versão gratuita, sem limites de quantidade de alunos e turmas, mas com recursos de gamificação limitados. Todos os recursos relatados neste trabalho estão disponíveis na versão gratuita, mas adotamos a versão paga.
} 
ferramentas de comunicação professor-aluno e aluno-aluno, espaços para disponibilização de material de estudo e diversos recursos de gamificação. Com um visual que combina fantasia e elementos medievais, os alunos podem criar e personalizar o seu avatar e trabalhar colaborativamente na plataforma. Nesta ferramenta os alunos podem acompanhar seu desempenho individual e ter acesso aos desempenhos individuais dos outros estudantes.

\subsection{Procedimentos}

Neste trabalho realizamos algumas modificações em relação ao modelo proposto por Werbach e Hunter (2012) visando adaptar ao contexto educacional. Todas as seis fases foram mantidas, contudo elas foram nomeadas de maneira distinta e : 1) definir os objetivos de gamificação; 2) delinear as metas comportamentais; 3) caracterizar os jogadores; 4) elaborar os ciclos de atividades; 5) garantir a diversão dos jogadores; 6) implementar as ferramentas apropriadas.

\subsubsection{Definir dos objetivos de gamificação}

O principal objetivo ao gamificar a disciplina consiste em promover uma experiência de aprendizagem de conceitos de algoritmos e programação que seja envolvente, desafiadora e significativa para os alunos. Espera-se que os alunos se sintam desafiados a aprender do mesmo modo que se sentem desafiados quando jogam os seus jogos prediletos.

Como objetivos específicos espera-se que os alunos possam compreender como os conteúdos apresentados estão presentes e podem ser uteis em aspectos reais de suas vidas. Outro objetivo específico consiste em desenvolver entre os alunos uma respeitosa relação entre eles próprios, com o espaço escolar e com a professora.

\subsubsection{Delinear as metas comportamentais}

Segundo Werbach e Hunter (2012), as metas comportamentais devem ser concretas e específicas. Estas metas devem refletir os comportamentos a serem desenvolvidos pelos jogadores e devem promover os objetivos de gamificação elencados na fase anterior. Neste trabalho, as metas comportamentais referem-se aos comportamentos e atitudes como cidadão a serem desenvolvidos: como a relação com os colegas e os professores e com o ambiente escolar, o protagonismo, a curiosidade, dedicação aos estudos.

Uma vez que a disciplina foi apresentada aos alunos como um jogo, os objetivos comportamentais e atitudinais foram apresentados como as regras que iriam guiar o ganho/ a perda de pontuação ao longo da disciplina. Foram traçados os seguintes objetivos comportamentais: (a) prestar atenção às aulas; (b) não atrapalhar os colegas; (c) não atrapalhar a aula; (d) não desrespeitar a professora; (e) manter o espaço escolar limpo e organizado; (f) resolver desafios; (g) realizar as pesquisas solicitadas; (h) realizar os trabalhos para casa; (i) realizar as atividades em sala; (j) participar ativamente $^{4}$. Estes objetivos foram traçados com base nas necessidades elencadas pela

\footnotetext{
${ }^{4}$ Tendo em vista não desprivilegiar os mais introvertidos, optou-se por considerar sugestões de temas, filmes, jogos e outra contribuições que influenciassem ou pudessem influenciar a aula sem necessariamente implicar em uma
} 
VI Congresso Brasileiro de Informática na Educação (CBIE 2017)

Anais do XXIII Workshop de Informática na Escola (WIE 2017)

professora em conjunto com orientações oferecidas pela coordenação.

\subsubsection{Caracterizar os jogadores}

Neste modelo buscamos caracterizar os participantes para estabelecer quais atividades e como estas serão desenvolvidas. Para este fim, os alunos foram convidados a preencher anonimamente dois formulários online. O primeiro formulário obteve 232 respostas válidas e teve como objetivo identificar informações gerais como a que turma o aluno pertence, sexo, se o aluno costumava jogar e caso sim, durante quantas horas semanais e quais os gêneros de jogos preferidos. O segundo formulário obteve 134 respostas válidas e teve como objetivo identificar de maneira mais específica as preferências como: quais os tipos de jogos que mais gostam (tradicionais, digitais, brincadeiras, etc.), quais os livros preferidos, quais os filmes, livros, seriados, animes e desenhos animados assistidos.

Nossa preocupação em compreender as preferências de entretenimento visa estabelecer referenciais sobre o que eles consideram divertido e quais gêneros de narrativas, quais personagens e quais arquétipos estão presentes no cotidiano deles para que os elementos a serem incorporados na gamificação promovessem um senso de pertencimento nos envolvidos, oferecendo contextualização e significado para o aprendiz.

\subsubsection{Elaborar os ciclos de atividades}

Os ciclos de atividades distinguem-se em dois tipos, conforme por Werbach e Hunter (2012): (a) engagement loops (ciclos curtos); (b) progression stairs (ciclos longos). Nos engagement loops, os jogadores são estimulados a realizarem as ações e estas ações resultam em feedbacks do sistema (como recompensas, por exemplo). Estes feedbacks por sua vez impulsionam o jogador a adotar certas ações e assim sucessivamente. Os ciclos curtos tem sido desenvolvido por meio dos objetivos comportamentais/atitudinais que são observados todas as aulas. Os alunos são recompensados/ penalizados conforme cumprem estes objetivos. Os seguintes elementos de design de jogos foram adotados neste tipo de ciclo: (a) componentes como pontos, rankings, níveis e virtual goods; (b) mecânicas como desafios, cooperação, feedbacks, transações, elementos de sorte ${ }^{5}$.

Os progression stairs, no entanto, oferecem uma perspectiva macro de toda a jornada do jogador. Os objetivos educacionais norteiam o desenvolvimento do ciclo longo. Neste primeiro semestre esperava-se estabelecer o ciclo longo considerando todo o ano letivo. No entanto, tem-se questionado a possibilidade de torná-lo bimestral ao longo de 2017.2. Os dois motivos para esta mudança são: acompanhar o ciclo de avaliações regulares da escola e oferecer feedbacks e gratificações em prazos mais curtos para os alunos. Os alunos parecem não conseguir estabelecer metas para um objetivo de tão longo prazo, porque a percepção é fragmentada devido aos testes e avaliações bimestrais.

participação em público.

${ }^{5} \mathrm{Na}$ versão original, os autores usam o termo stochastic elements e referem -se a aleatoriedade e a casualidade, remetendo ao uso de elementos que envolvem sorte como o uso de dados ou sorteios para bonificação, por exemplo. 
Neste trabalho, as etapas (5) Estruturação da diversão dos jogadores e (6) Implemente os elementos apropriados ainda não foram suficientemente desenvolvidas, de modo que não serão abordadas no presente trabalho. Os próximos passos para estas etapas são a) Utilizar os dados coletados na fase (3) e b) Usar a tipologia de Bartle (1996) para delinear quais os perfis de jogadores envolvidos. Estes dados serviriam para criar personas que permitam construir propostas de diversão que sejam condizentes com estes perfis e selecionar quais os componentes, mecânicas e dinâmicas para adequados para serem mantidos.

\section{Discussões}

Os alunos dos sextos e sétimos anos se mostraram mais empolgados com a plataforma e com os elementos de design de jogos adotados na disciplina. Eles se identificam com a proposta e se divertem ao verem que os personagens e elementos presentes em suas experiências de entretenimento também estão presentes no cotidiano escolar. Os alunos dos oitavos e nonos anos são adolescentes e demonstram maior interesse em recompensas que impactem suas notas nas disciplinas. No entanto, esta disciplina não faz parte da grade curricular, não sendo possível atribuir notas e isto deixa os alunos menos engajados propensos a desmerecem a disciplina. Eles se mostraram poucos interessados pela plataforma adotada e pelos recursos que ela oferece, sem importarem em acompanharem o seu desempenho individual, mesmo com a estética visual da plataforma sendo muito próxima dos jogos que a maioria deles afirmaram preferir jogar.

Um desafio em particular consiste em combinar adequadamente os elementos de design de jogos de maneira que seja considerada mais divertida pelos alunos mais velhos. Todavia, os alunos de todas as turmas mostraram-se plenamente satisfeitos com as competições de jogos, as brincadeiras e as estratégias baseadas em jogos utilizadas para abordar os conteúdos da disciplina. Uma possibilidade talvez seja optar por uma abordagem diferenciada para os oitavos e nonos anos que enfatize a narrativa e a progressão, suprimindo os componentes PBL como forma de recompensar os objetivos comportamentais e atitudinais.

Outro aspecto impactante tem sido o custo envolvido na manutenção do modelo de gamificação estabelecido considerando os perfis e as preferências de cada turma. Existe um grande esforço envolvido em: tomar nota das pontuações dos estudantes a cada aula e alimentar a plataforma com os dados obtidos para garantir que os alunos possam acompanhar o seu desempenho individual; alimentar a plataforma com outros insumos como narrativas, materiais de estudos, desafios adicionais e outros. No intuito de garantir a diversão faz-se necessário investir mais tempo do que o habitual em modelos de aula tradicionais para preparar estratégias que sejam adequadas aos distintos perfis e preferências.

\section{Considerações Finais}

O modelo conceitual de gamificação apresentado neste trabalho baseia-se na premissa de que as dinâmicas, elementos e componentes dos jogos oferecem um tipo 
particularmente desafiador e envolvente de aprendizagem.

Os elementos de design de jogos possuem ainda características muito valorizadas em espaços de aprendizagem de programação, por este motivo acredita-se que adotar a gamificação seja uma estratégia adequada para fomentar a aprendizagem dos conteúdos abordados nesta disciplina. Notadamente, a proposta apresentada constitui-se em uma versão em desenvolvimento e sob avaliação e serão realizados refinamentos e melhorias. Um dos principais desafios constatados consiste em estabelecer uma combinação adequada dos elementos, componentes e dinâmicas de jogos de maneira que seja considerada divertida pelos alunos dos oitavos e nonos anos. O próximo passo consiste em refinar a abordagem proposta a partir da criação de personas que considerem o perfil do aluno, as preferências de entretenimento e o perfil segundo a tipologia de Bartle (1996). Outros passos consistem em avaliar o impacto da gamificação no engajamento dos alunos e estabelecer relações entre o engajamento e o desempenho dos alunos na aprendizagem dos conceitos.

Neste trabalho foi apresentado a elaboração e incorporação de um modelo de gamificação no ensino de programação para crianças e adolescentes. O presente trabalho está sendo desenvolvido em uma disciplina experimental de Pensamento Computacional em uma escola da rede particular de ensino em Recife, Pernambuco. Espera-se que este trabalho possa ser relevante para pesquisadores e educadores interessados na elaboração, adoção e avaliação de modelos de gamificação em sala de aula, sobretudo em experiências de ensino de programação e do pensamento computacional na educação básica.

\section{Agradecimentos}

As autoras agradecem a Olivia Tavares Cunha pela ajuda na sistematização dos dados obtidos.

\section{Referências}

Aguiar, J. Experiência baseada em Gamificação no Ensino sobre Herança em Programação Orientada a Objetos. In: Anais dos Workshops do Congresso Brasileiro de Informática na Educação. 2015. p. 1444.

Alves, L. R. G., Minho, M. R. S. e Diniz, M. V. C. (2014). Gamificação: diálogos com a educação. In: Fadel, L. M. et al. (Org.). "Gamificação na Educação" (pp. 74-97). São Paulo, Pimenta Cultural.

Bartle, R. (1996). Hearts, clubs, diamonds, spades: Players who suit MUDs. Journal of MUD research, v. 1, n. 1, p. 19.

Borges, S. D. S., Reis, H. M., Durelli, V. H., Bittencourt, I. I., Jaques, P. A., e Isotani, S. Gamificação aplicada à educação: um mapeamento sistemático. In: Simpósio Brasileiro de Informática na Educação-SBIE. 2013. p. 234.

Brito, A., e Madeira, C. XP \& Skills: gamificando o processo de ensino de introdução a 
VI Congresso Brasileiro de Informática na Educação (CBIE 2017)

Anais do XXIII Workshop de Informática na Escola (WIE 2017)

programação. In: Anais dos Workshops do Congresso Brasileiro de Informática na Educação. 2015. p. 1124.

Campos, A., Gardiman, R., e Madeira, C. (2015) Uma ferramenta gamificada de apoio à disciplina introdutória de programação. In: XXIII Workshop sobre Educação em Computação. Maceió: Alagoas.

Chou, Y. (2015). "Octalysis: Complete gamification framework". Disponível em: http://www.yukaichou.com. Junho, 2017.

Falcão, A. P., Leite, M. D., e Tenório, M. M. (2014). Ferramenta de apoio ao ensino presencial utilizando gamificação e design de jogos. In: Simpósio Brasileiro de Informática na Educação-SBIE. p. 526.

Fiqueiredo, M., Paz, T., e Junqueira, E. (2015) Gamificação e educação: um estado da arte das pesquisas realizadas no Brasil. In: IV Congresso Brasileiro de Informática na Educação. Anais dos Workshops do Congresso Brasileiro de Informática na Educação. Maceió: Alagoas.

Gomes, T. C. S., Tedesco, P. C. A. R. e Melo, J. C. B. (2016) Jogos no Design de Experiências de Aprendizagem de Programação Engajadoras. In: V Congresso Brasileiro de Informática na Educação - Anais da Jornada de Atualização em Informática na Educação. Uberlândia: Minas Gerais.

Guzdial, M. (2015) Learner-Centered Design of Computing Education: Research on Computing for Everyone. Synthesis on Human-Centered Informatics. Morgan \& Claypool Publishers.

Lee, J. J. ; Hammer, J. Gamification in Education: What, How, Why Bother? . 2011.

Lima, Y. C. C. A. (2017) "Gamificação na educação básica: a construção de um modelo". Dissertação de Mestrado. Centro de Informática: Universidade Federal de Pernambuco. Recife, Pernambuco.

Maekawa, C., Nagai, W., e Izeki, C.Relato de Gamificação da disciplina Projeto e Análise de Algoritmos do curso de Engenharia de Computação. (2015) In: Anais dos Workshops do Congresso Brasileiro de Informática na Educação. Maceió: Alagoas.

McGonigal, J. (2012) A realidade em jogo. Rio de Janeiro: Editora Best Seller.

Raposo, E. H. S., e Dantas, V. (2016) O Desafio da Serpente - Usando gamification para motivar alunos em uma disciplina introdutória de programação. In: Simpósio Brasileiro de Informática na Educação. p. 577.

Schlemmer, E. e Lopes, D. Q. (2016) Avaliação da aprendizagem em processos gamificados: desafios para apropriação do método cartográfico. In: Jogos digitais e aprendizagem: fundamentos para uma prática baseada em evidências. Alves, L. e Coutinho, I. J (Orgs.). Campinas: Editora Papirus.

Silva, T., Melo, J., e Tedesco, P. (2016) Um modelo para promover o engajamento estudantil no aprendizado de programação utilizando gamification. In: Anais dos Workshops do Congresso Brasileiro de Informática na Educação. p.71.

Veen, W., e Vrakking, B. Homo Zappiens: educando na era digital. Artmed Editora, 2009. 